\title{
How Long a Motivation May Last?
}

\author{
Nasim Habibzadeh* \\ PhD in Sport Science, Department of Sport Science, Teesside University, UK \\ *Corresponding Author: Nasim Habibzadeh, PhD in Sport Science, Department of Sport Science, \\ Teesside University, $U K$

\begin{abstract}
Motivation is kind of goal which ones could have over short or long terms in life. It could include both intrinsic and extrinsic types. Intrinsic motivations are composed of long term goals which associated with the internal individual's motivation whereas extrinsic motivations are empowered by external environments. Correspondingly, with considering the individual endurances, the type of hardships in different type of motivations is vary. In this between, the individual devotions in relation to their goal are determinate factors. Some people devoted their entire life to their goals, so how determinate you are?
\end{abstract}

Keywords: Motivation, time, hardship, endurance

\section{INTRODUCTION}

Motivation is kind of thought which ones have toward willingness and goals in psychological terms [1]. Successful individual always have high level of motivations although they have to pass of high level of hardship pass way also (Fig1).The motivated individual owing to the high level of endurance, have strong desires in any actions they execute. Highly motivated individual are like athlete or life time scientists in practice. They continuously work without thinking that how hard a task could be in order to achieve to a specific goal. Motivated people have high level of inspirations by themselves and can be inspired by any factor in space or time [2].

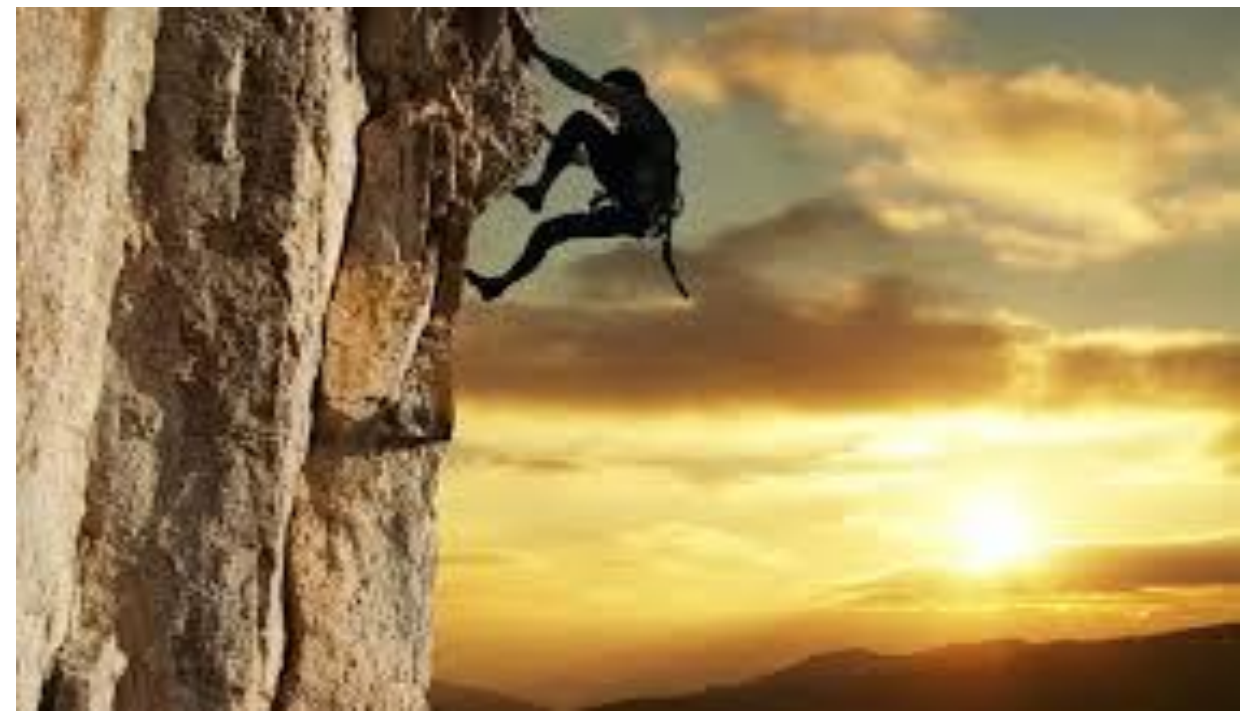

Fig1. Motivation theme

Motivations origin from two intrinsic and extrinsic sources. The intrinsic motivations refers to the factors such curiosity, learning which can be permanent as they are kind of internal inception from the birth time whereas the extrinsic motivation are reinforced by external factors such as some rewards or even punishments which can end up to a specific point of time [3,4] (Fig2). Nonetheless, the intrinsic motivations could be life-changing as one's can go by unthinkable stages to achieve a goal. This is why, some novel discoveries using highly level of devotions will happen in certain fields' .This might cost one's whole life among different goals compared to other individual across globs. 


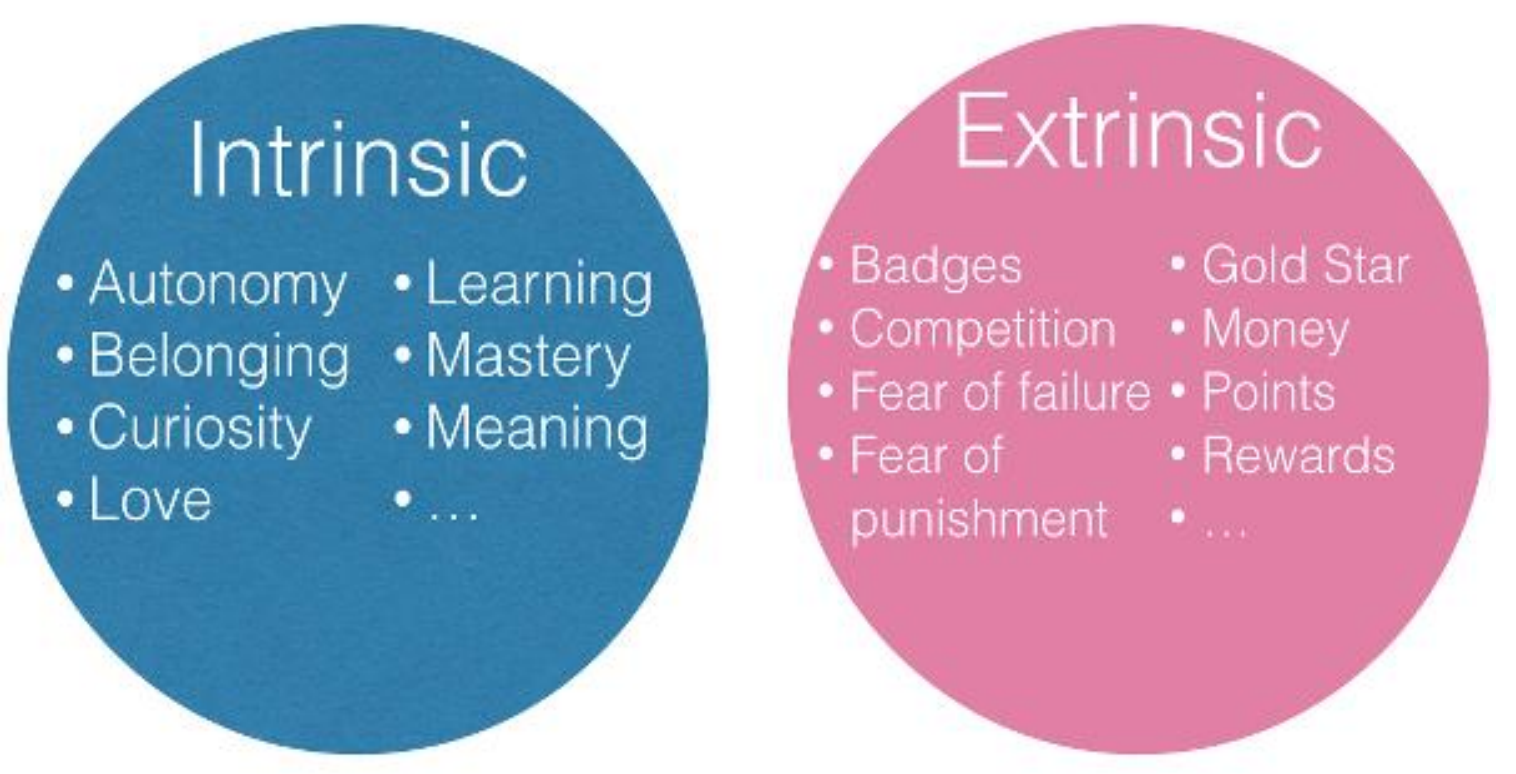

Fig2. The types of motivations

\section{SUMMARY}

Motivation is a psychological behavioral demand toward a long - or - short term goal .The long- term motivations are intrinsic and short-terms motivations are extrinsic. The short -term motivations are limited to the time among different people whilst high level motivations always create people such as elites or scientists for example. In this relations, owing to strong level of devotions, one's can go for a goal in a non - stop - manner to discover or create something new to prime a goal for other human kinds toward more feasible and enjoyable life.

\section{REFERENCES}

[1] Gollowitzer, P. The psychology of action: Linking cognition and motivation to behavior. New York: Guilford,1996

[2] Thompson T, Davidson JA, \& Barber J G. Self-worth protection in achievement motivation: Performance effects and attributional behavior. Journal of Educational Psychology. 1995:87, 598-610

[3] Maslow AH. A Theory of Human Motivation. Psychological Review. 1943; 50: 370-396

[4] Vroom VH. Work and motivation. New York: Wiley; 1964.

Citation: Nasim Habibzadeh. "How Long a Motivation May Last?" International Journal of Sports and Physical Education (IJSPE), vol 5, no. 3, 2019, pp. 23-24. doi: http://dx.doi.org/10.20431/2454-6380.0503005.

Copyright: () 2019 Authors. This is an open-access article distributed under the terms of the Creative Commons Attribution License, which permits unrestricted use, distribution, and reproduction in any medium, provided the original author and source are credited. 